\title{
Case-control study of 24 hour ambulatory blood pressure in patients with obstructive sleep apnoea and normal matched control subjects
}

Christopher W H Davies, Joy H Crosby, Rebecca L Mullins, Charles Barbour, Robert J O Davies, John R Stradling

\begin{abstract}
Background-There is considerable debate regarding the relationship between obstructive sleep apnoea (OSA) and hypertension. It is unclear whether OSA is an independent vascular risk factor as studies attempting to assess this association have produced conflicting results because of confounding variables such as upper body obesity, alcohol, and smoking. A case-control study of 24 hour ambulatory blood pressure was undertaken in patients with OSA and matched controls to assess whether OSA is an independent correlate of diurnal hypertension.

Methods-Forty five patients with moderate to severe OSA and excessive daytime sleepiness were matched with 45 controls without OSA in a sleep study. Matched variables included age, body mass index (BMI), alcohol, cigarette usage, treated hypertension, and ischaemic heart disease. Upper body obesity was compared by waist:hip and waist:height ratios; 24 hour ambulatory blood pressure recordings were performed (before treatment for OSA) in all subjects.
\end{abstract}

Results-Patients with OSA had significantly increased mean (SD) diastolic blood pressure ( $\mathrm{mm} \mathrm{Hg}$ ) during both daytime (87.4 (10.2) versus 82.8 (9.1); $\mathrm{p}=0.03$, mean difference $4.6(95 \%$ CI 0.7 to 8.6$)$ and night time (78.6 (9.3) versus 71.4 (8.0); p<0.001, mean difference 7.2 (95\% CI 3.7 to 10.6)), and higher systolic blood pressure at night $(119.4(20.7)$ versus 110.2 (13.9); $\mathrm{p}=0.01$, mean difference 9.2 (95\% CI 2.3 to 16.1$)$ ). The nocturnal reduction in blood pressure ("dipping") was smaller in patients with OSA than in control subjects.

Conclusions-Compared with closely matched control subjects, patients with OSA have increased ambulatory diastolic blood pressure during both day and night, and increased systolic blood pressure at night. The magnitude of these differences is sufficient to carry an increased risk of cardiovascular morbidity. The slight excess of upper body fat deposition in the controls may make these results conservative.

(Thorax 2000;55:736-740)

Keywords: obstructive sleep apnoea; ambulatory blood pressure
Obstructive sleep apnoea (OSA) is characterised by the repetitive partial or complete interruption of airflow during sleep as a result of pharyngeal collapse. Each of these events fragments sleep, causing daytime sleepiness, and involves a substantial transient post-apnoeic rise in blood pressure rise. ${ }^{12}$ As well as these acute night time effects, patients with OSA have an excess of daytime hypertension and vascular risk. ${ }^{3}$ OSA is extremely prevalent in the normal community with $0.3-6 \%$ of adult men having some abnormality ${ }^{45}$ (depending on the exact definition). This has led to the assertion that OSA may be a significant community vascular risk factor. Leading USA authorities have suggested that OSA may be as important a vascular risk factor as diabetes. ${ }^{6}$ In the UK this remains highly contentious, with independent authorities arguing that this conclusion is currently untenable due to inadequate consideration of confounding variables, particularly obesity and body fat distribution. ${ }^{7}$ The British Medical fournal has gone as far as to say that OSA may "not be a disease at all". The need for studies to examine the relationship between OSA and blood pressure while controlling for important confounding effects to clarify this important question has been emphasised. ${ }^{79}$

This study reports the results of a case controlled study of ambulatory blood pressure (ABP) in OSA where the control subjects have been selected to provide in vivo correction for the important confounders of the relationship between OSA and blood pressure. This analysis clarifies the question of whether OSA is an independent correlate of blood pressure and hence likely to be aetiological in this relationship.

\section{Methods}

SUBJECTS

Obstructive sleep apnoea

Patients with OSA were identified prospectively through the outpatient Sleep Clinic. All patients were men aged between 30 and 80 years, with excessive daytime sleepiness and proven obstructive sleep apnoea. All subjects had an overnight sleep study (Visi-Lab System, Stowood Scientific Instruments, Oxford, UK) recording pulse rate and arterial oxygen saturation $\left(\mathrm{SaO}_{2}\right)$, movement, and sound with video recording. Excessive daytime sleepiness was defined as an Epworth Sleepiness Score (ESS) of $\geqslant 10$, and obstructive sleep apnoea was defined as $>10$ per hour falls in arterial
23 March 2000

19 May 2000 
Table 1 Mean (SD) demographic details of patients with OSA and control subjects

\begin{tabular}{|c|c|c|c|}
\hline & $\begin{array}{l}\text { Patients with OSA } \\
(n=45)\end{array}$ & $\begin{array}{l}\text { Control subjects } \\
(n=45)\end{array}$ & p value \\
\hline Age (years) & $51.7(10.4)$ & $52.2(10.4)$ & NS \\
\hline Weight (kg) & $93.1(10.1)$ & $94.1(10.3)$ & NS \\
\hline Height (m) & $1.74(0.08)$ & $1.75(0.07)$ & NS \\
\hline $\mathrm{BMI}\left(\mathrm{kg} / \mathrm{m}^{2}\right)$ & $30.9(2.8)$ & $30.5(2.4)$ & NS \\
\hline Waist $(\mathrm{cm})$ & $103(9.3)$ & $107(7.6)$ & $<0.01$ \\
\hline $\operatorname{Hip}(\mathrm{cm})$ & $107(6.9)$ & $109(7.3)$ & NS \\
\hline Waist/hip ratio & $0.96(0.06)$ & $0.99(0.04)$ & $<0.01$ \\
\hline Waist/height ratio & $0.59(0.06)$ & $0.61(0.04)$ & $<0.05$ \\
\hline $\operatorname{Neck}(\mathrm{cm})$ & $42.8(2.9)$ & $41.9(2.1)$ & NS \\
\hline ESS & $15.9(3.1)$ & $7.1(3.2)$ & $<0.0001$ \\
\hline$>4 \%$ falls in $\mathrm{SaO}_{2} / \mathrm{h}$ & $29.1(13.4)$ & $1.7(1.6)$ & $<0.0001$ \\
\hline Time of waking & $07: 45(1: 05)$ & $7: 58(1: 13)$ & NS \\
\hline \multicolumn{4}{|l|}{ Past history } \\
\hline Hypertension & 6 & 6 & \\
\hline Ischaemic heart disease & 3 & 3 & \\
\hline \multicolumn{4}{|l|}{ Smoking } \\
\hline Never & 12 & 12 & \\
\hline Ex/current & 33 & 33 & \\
\hline
\end{tabular}

$\mathrm{BMI}=$ body mass index $; \mathrm{ESS}=$ Epworth Sleepiness score; $\mathrm{SaO}_{2}=$ arterial saturation.

saturation $\left(\mathrm{SaO}_{2}\right)$ of $>4 \%$ confirmed as being caused by upper airway obstruction on the video recording.

Normal controls

Control subjects were taken from the register of a general practice in Bicester, Oxfordshire and identified as potential matched controls for the OSA subjects according to the criteria described below. Control subjects received a written invitation from their GP to take part in the study and subsequently from the Sleep Unit.

All control subjects had a home sleep study using an RM50 portable monitor (Parametric Recorders, London, UK). The RM50 was programmed to record between 23:00 and 07:00 hours, recording heart rate, $\mathrm{SaO}_{2}$, snoring, body position, and chest wall movements. Control subjects were excluded when they exhibited $>5$ per hour falls in $\mathrm{SaO}_{2}$ of $>4 \%$ during the night of the recording. Symptoms suggestive of OSA were not one of the exclusion criteria.

MATCHING

All patients were assessed for weight, height, body mass index (BMI) $\left(\mathrm{kg} / \mathrm{m}^{2}\right)$, neck circumference at the level of the cricothyroid membrane, waist circumference at the level of the umbilicus, maximal hip circumference, cigarette consumption, alcohol consumption, medications, and past medical history. Upper body obesity was assessed by calculation of the waist:hip and waist:height ratios. ${ }^{10}$ Controls were matched with OSA patients by age $( \pm 10 \%)$, BMI $( \pm 5 \%)$, alcohol $(>10$ or $<10$ units/week), smoking (never versus ex/ current), treated hypertension, ischaemic heart disease (documented history of angina and/or previous myocardial infarction), and diabetes. A control subject was selected for each patient with OSA by matching for all these variables. OSA subjects for whom we could not identify suitable matching control subjects were excluded from the study.

AMBULATORY BLOOD PRESSURE RECORDINGS Twenty four hour ambulatory blood pressure recordings were performed as outpatients during normal activities. For patients with OSA recordings were performed before commencing any form of treatment for OSA. Blood pressure was recorded using a validated ambulatory recorder (TM2420, Takeda A\&D, Japan). ${ }^{11}$ This recorder measures blood pressure using Korotkov sounds. Where subjects had unreliable recordings with this technique, blood pressure was measured using the oscillotonometric method (TM2422, Takeda A\&D, Japan). The patients' arm circumference was measured at the biceps level and an appropriate sized arm cuff (either $20-31 \mathrm{~cm}$ or $28-36 \mathrm{~cm}$ ) was used. The machine was programmed for cuff inflation measurements every 30 minutes throughout the 24 hour period, including night time.

Patients recorded the time they retired to bed in the evening and subsequent time of waking the following day, enabling identification of the sleep period. Blood pressure was analysed (systolic and diastolic means) for the overall 24 hour period, daytime (from waking to bedtime) and night time (from retiring to bed until waking) for each individual. In addition, the 24 hour profile of blood pressure values was plotted for the OSA patients and the control group, and nocturnal blood pressure dipping was assessed by calculating the difference between mean daytime and night time values.

All subjects gave consent to take part in the study. The protocol for the study was approved by the Central Oxford Research ethics committee (number 94.086).

DATA ANALYSIS

Blood pressure of the patients with OSA and control subjects was compared using paired $t$ tests and the results are expressed as mean (SD). Statistical analysis was performed using the SPSS statistical software package (SPSS Software, SPSS Inc, Chicago, USA). Analysis was performed initially for all patients and also on a subgroup from which patients with treated hypertension were excluded.

\section{Results}

\section{SUBJECTS}

A total of 90 subjects (45 matched pairs) were included in the study. The demographic characteristics of the 90 patients are shown in table 1 . The severity of sleep apnoea in the patients ranged from 10.4 to $66.6 \mathrm{dips} /$ hour in $\mathrm{SaO}_{2}$ of $>4 \%$ compared with control subjects (0-5 dips/hour; $\mathrm{p}<0.001$ ). As expected, the patients with OSA had higher levels of subjective sleepiness than the control subjects (mean (SD) ESS 15.9 (3.1) versus 7.1 (3.2); $\mathrm{p}<0.001)$.

Six patients with OSA fulfilling the entry criteria were excluded as they were impossible to match with a suitable control subject, predominantly because of excessive BMI $\left(>35 \mathrm{~kg} / \mathrm{m}^{2}\right)$ and/or matching for treated hypertension.

The two patient groups were closely matched as intended. The control subjects had slightly but significantly higher waist:hip and waist:height ratios, indicating greater upper body obesity in the controls than in the patients 
Table 2 Mean (SD) overall, daytime, and night time ambulatory blood pressures in all patients with OSA and excluding treated hypertensive subjects compared with control subjects

\begin{tabular}{|c|c|c|c|c|c|c|c|c|}
\hline & $\begin{array}{l}\text { Patients with } \\
\text { OSA }(n=45)\end{array}$ & $\begin{array}{l}\text { Control subjects } \\
(n=45)\end{array}$ & $\begin{array}{l}\text { Mean difference } \\
(95 \% \mathrm{CI})\end{array}$ & p value & $\begin{array}{l}\text { Patients with } \\
\text { OSA excluding } \\
\text { hypertensives } \\
(n=39)\end{array}$ & $\begin{array}{l}\text { Control subjects } \\
\text { excluding } \\
\text { hypertensives } \\
(n=39)\end{array}$ & $\begin{array}{l}\text { Mean difference } \\
(95 \% \mathrm{CI})\end{array}$ & p value \\
\hline Overall SBP & $128.2(17.2)$ & $123.9(13.8)$ & $4.3(-1.8$ to 10.3$)$ & 0.18 & $127.6(18.0)$ & $122.6(13.5)$ & $5.0(-1.9$ to 11.8$)$ & 0.17 \\
\hline Overall DBP & $83.7(9.5)$ & $78.6(8.8)$ & $5.1(1.2$ to 8.6$)$ & $0.01^{\star}$ & $83.2(9.0)$ & $78.0(8.5)$ & $5.2(1.3$ to 9.1$)$ & $0.01^{\star}$ \\
\hline Daytime SBP & $132.9(16.5)$ & $131.2(14.8)$ & $1.7(-4.1$ to 7.6$)$ & 0.57 & $132.4(17.2)$ & $130.3(14.6)$ & $2.1(-4.5$ to 8.64$)$ & 0.55 \\
\hline Daytime DBP & $87.4(10.2)$ & $82.8(9.1)$ & $4.6(0.7$ to 8.6$)$ & $0.03^{\star}$ & $87.1(9.6)$ & $82.3(8.9)$ & $4.8(0.7$ to 9.0$)$ & $0.03^{\star}$ \\
\hline Night time SBP & $119.4(20.7)$ & $110.2(13.9)$ & $9.2(2.3$ to 16.1$)$ & $0.01^{\star}$ & $118.4(22.0)$ & $108.7(13.2)$ & $9.7(1.7$ to 17.7$)$ & $0.02^{\star}$ \\
\hline Night time DBP & $78.6(9.3)$ & $71.4(8.0)$ & 7.2 (3.7 to 10.6$)$ & $<0.001^{\star}$ & $77.7(9.2)$ & $70.7(8.0)$ & $7.0(3.3$ to 10.8$)$ & $<0.001^{\star}$ \\
\hline
\end{tabular}

SBP = systolic blood pressure; DBP = diastolic blood pressure.

with OSA. Three pairs had a matching history of ischaemic heart disease and six pairs matched for antihypertensive medication.

AMBULATORY BLOOD PRESSURE

Diastolic blood pressure in patients with OSA was significantly higher than in controls during the daytime, night time, and overall (table 2). Patients with OSA also had a significantly higher night time systolic blood pressure but daytime and overall systolic blood pressure was not significantly different from control subjects. Exclusion of the subjects who received antihypertensive medication made little difference to these results (table 2).

Figure 1 shows the 24 hour blood pressure profile of OSA patients and their controls. In patients with OSA increased diastolic blood pressure was observed predominantly during sleep, between midnight and 08:00 hours, but was also significantly different between 16:00 and 19:30 hours. Systolic blood pressure was similar between the two groups throughout the day and was only significantly different between 02:00 and 08:30 hours. This increase in systolic blood pressure in subjects with OSA is largely caused by a reduction in the normal nocturnal fall in blood pressure (day to night fall in systolic blood pressure $13.5 \mathrm{~mm} \mathrm{Hg}$ and $21.0 \mathrm{~mm} \mathrm{Hg}$ in OSA subjects and controls, respectively; $p<0.005)$. There was less day to night fall in diastolic blood pressure between the two groups $(8.8 \mathrm{~mm} \mathrm{Hg}$ versus

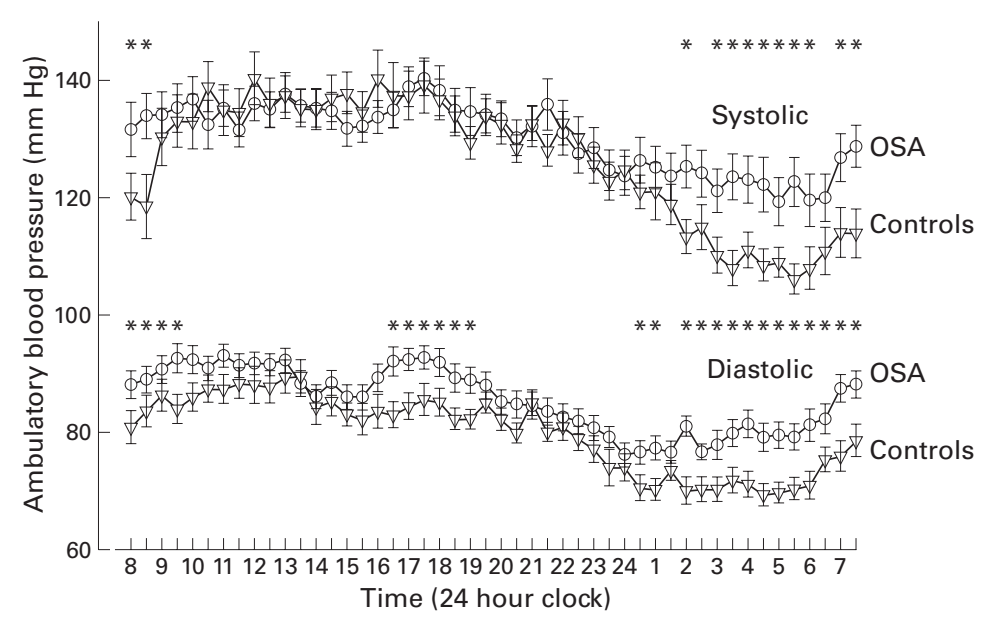

Figure 1 Mean (SE) 24 hour systolic and diastolic blood pressure profiles for patients with OSA $(n=45)$ and their matched controls $(n=45)$. Note the clear differences at night with a reduced nocturnal fall in blood pressure in the patients with OSA, the diastolic differences during the day, and a short persistence of the systolic differences into the early morning. Asterisks indicate times at which the individual differences reach a statistically significant level of $p<0.05$ (Student's $t$ test).
$11.4 \mathrm{~mm} \mathrm{Hg}$ in OSA subjects and controls; $\mathrm{p}=0.13)$.

\section{Discussion}

This study reports 24 hour ambulatory blood pressure profiles of untreated patients with OSA compared with carefully matched control subjects drawn from the community where the confounding effects of obesity, its distribution, and other relevant variables are controlled. Patients with OSA had significantly higher diastolic blood pressure during the night time and daytime, and higher systolic blood pressure during the night, with a reduction in the fall in nocturnal blood pressure seen in normal subjects. The mean increase in diastolic blood pressure was $5 \mathrm{~mm} \mathrm{Hg}$ compared with control subjects, a difference that is likely to be associated with an increased relative risk of both stroke and coronary heart disease. ${ }^{12}$ In addition, if the absence of a nocturnal blood pressure dip in these patients carries the same prognostic significance as it does in essential hypertension, ${ }^{12}{ }^{13}$ this might in theory increase the relative risk of stroke by approximately $40 \%$ and coronary heart disease by approximately $15 \% .^{12}$ Intervention studies are now needed where the standard treatments of OSA are compared with placebo treated controls to establish if these blood pressure abnormalities correct with treatment.

This study also highlights the difficulty of performing carefully matched case-control series in patients with OSA. Obesity is the predominant risk factor for the development of OSA, and we screened a large population of general practice subjects before being able to find BMI-matched control subjects who did not have overt OSA on their sleep study. In addition, we have matched patients for the other confounding variables (age, smoking, alcohol, and past medical history including cardiovascular disease) so that the effects of OSA could be examined in isolation. However, we had to exclude six subjects from the final analysis because we were unable to find suitable matched controls. The differences in blood pressure we have observed cannot be explained by a difference in body fat distribution as the control group actually had slightly greater upper body obesity, as indicated by higher waist:hip and waist:height ratios (table 1 ), and thus would have been expected to have higher blood pressures since upper body obesity is a strong predictor of arterial pressure. ${ }^{14}$ Overall, however, body fat distribution in both groups was predominantly central as indicated 
by waist:hip ratios of more than 0.95 in $60 \%$ of subjects with OSA and $80 \%$ of controls.

Not surprisingly, a number of the control subjects were snorers since they shared the same dominant risk factor (obesity) as patients with OSA. A number of studies have reported an association between snoring and hypertension which may persist after allowing for obesity. ${ }^{15-18}$ The use of a desaturation index of $\leqslant 5$ per hour to define normality may have included a few subjects with apnoea/ hypopnoea indices (AHI) higher than this value. However, any association between mild sleep apnoea or snoring and blood pressure will have attenuated the difference in blood pressure seen in our study and strengthens the significance of the differences found between our patients with OSA and the matched controls. Snoring could lead to sleep fragmentation and acute rises in blood pressure, leading to sustained blood pressure effects, and thus the difference between OSA subjects and a nonsnoring population may be even greater than we have found. However, the use of control subjects selected from the community is preferable to the use of sleep clinic patients who are found to have AHI values below a certain figure.

Other studies have investigated the relationship between OSA, snoring, and blood pressure in cohorts of patients attending sleep clinics. Three studies by Hoffstein have examined blood pressure in $372,{ }^{19} 611,{ }^{20}$ and $2677^{21}$ sleep clinic referrals. In the first study ${ }^{19}$ blood pressure recordings were taken at the first clinic visit or on the evening of the sleep study. The severity of sleep apnoea and the mean nocturnal oxygen saturation were independently associated with a small increase in diastolic blood pressure. In the second series ${ }^{20}$ blood pressure data were available on the evening and morning of the sleep study and the investigators found that apnoeic subjects had higher blood pressures $(2 \mathrm{~mm} \mathrm{Hg}$ ) in the morning than those without apnoeas or hypoxaemia. The most recent study ${ }^{21}$ found that, in patients with the most severe OSA (AHI >50) the systolic blood pressure before rising in the morning was $15.3 \mathrm{~mm} \mathrm{Hg}$ higher than sleep laboratory "controls" with AHI values of $\leqslant 10$ (smaller differences were found if confounding variables were allowed for). The comparable diastolic blood pressure was $8.7 \mathrm{~mm} \mathrm{Hg}$. Their results are similar to our values between $7: 30$ and 8:30 hours, the usual rising time in our subjects. A similar report by Grunstein ${ }^{22}$ showed a progressively increased single morning blood pressure in patients with increasingly severe OSA (quantified by minimum night time oxygen saturation and respiratory disturbance index). In the Wisconsin Sleep Cohort Study $^{23}$ an association was observed between the degree of sleep disordered breathing using apnoea/hypopnoea (AHI) index and both systolic and diastolic blood pressures in a community population. Further results in this community using 24 hour data ${ }^{24}{ }^{25}$ showed that daytime blood pressure differences in those with an AHI of $>5 /$ hour were greatest in the first three hours after sleep. Similarly, Wilcox et $a l^{26}$ reported a fall in blood pressure in OSA patients successfully treated with nasal continuous positive airway pressure (nCPAP) compared with those receiving inadequate treatment. In these patients the 24 hour blood pressure profiles showed that the maximal daytime differences in pressure before and after nCPAP were in the morning hours after waking. In an uncontrolled study of nCPAP in 26 patients with OSA Minemura et $a l^{27}$ found falls in both the diastolic $(4 \mathrm{~mm} \mathrm{Hg})$ and systolic $(5 \mathrm{~mm} \mathrm{Hg})$ pressures at night but a fall in only the diastolic pressure $(3 \mathrm{~mm} \mathrm{Hg})$ during the day. This shows that studies using ambulatory blood pressure provide more information about the 24 hour blood pressure profile than single values. In particular, morning values overestimate the overall daytime differences, particularly in systolic blood pressure.

We have observed findings compatible with these reports using ambulatory blood pressure monitoring. There is a significant increase in both the systolic and diastolic blood pressure at night in patients with OSA, which persists briefly into the morning in the case of the systolic pressure but for more of the day in the case of the diastolic pressure. A similar smaller study from Oxford ${ }^{28}$ compared ambulatory blood pressures in 18 subjects with OSA and matched control subjects but found no significant differences between daytime or night time pressures. However, patients with OSA had a fall in night time systolic blood pressures after treatment. This study may have been underpowered to detect small differences between the groups and led us to repeat this study with a larger number of subjects. Apart from the obvious advantage of using 24 hour ambulatory blood pressure recording in all subjects, the current study is different from many of the previous reports as it includes a control group selected from the community rather than using non-apnoeic referrals to the sleep clinic as the control subjects.

The 24 hour blood pressure profiles of patients with untreated OSA and their matched controls (fig 1) clearly demonstrate the diurnal pattern of differences in blood pressures. Unfortunately we did not ask subjects to record a sleep chart during their 24 hour study other than recording their bedtime and time of rising in the morning, and it is possible that the hypersomnolent OSA subjects fell asleep after lunch and/or in the early evening, thus falsely lowering their daytime blood pressure towards those of the control subjects. Close inspection of the 24 hour profiles suggest this is a possibility, particularly between 13:00 and 15:30 hours and in the evening on the diastolic line. This may have obscured further significant daytime differences in both the systolic and diastolic blood pressures.

In conclusion, we have found that the syndrome of OSA, defined by excessive daytime sleepiness and oxygen desaturation $(>4 \%)$ dip rate of $>10 /$ hour, is associated with an increase in diastolic blood pressure during both the night and daytime. The rise in diurnal diastolic blood pressure is of sufficient magnitude to carry an excessive risk of cardiovascular morbidity for 
patients with OSA. This may also be true of the night time figures alone, particularly if this attenuated nocturnal dipping carries a similar adverse prognostic significance to that in essential hypertension.

This study was partially funded by a grant from the Oxfordshire Health Services Research Committee.

Conflicts of interest: none

1 Ringler J, Basner RC, Shannon R, et al. Hypoxemia alone does not explain blood pressure elevations after obstructive apneas. F Appl Physiol 1990;69:2143-8.

2 Davies RJO, Belt PJ, Robert SJ, et al. Arterial blood pressure responses to graded transient arousal from sleep in normal responses to graded transient arousal from

3 Silverberg DS, Oksenberg A. Essential hypertension and abnormal upper airway resistance during sleep. Sleep 1997; 20:794-805.

4 Stradling JR, Crosby JH. Predictors and prevalence of obstructive sleep apnoea and snoring in 1001 middle aged men. Thorax 1991;46:85-90.

5 Young T, Palta M, Dempsey J, et al. The occurrence of sleep-disordered breathing among middle-aged adults. $N$ Engl f Med 1993;328:1230-5.

6 Phillipson EA. Sleep apnea: a major public health problem. $N$ Engl f Med 1993;328:1271-3.

7 Wright J, Johns R, Watt I, et al. Health effects of obstructive sleep apnoea and the effectiveness of continuous positive airways pressure: a systematic review of the research evidence. BMF 1997;314:851-60.

8 Anonymous. Deep and shallow truths. BMF 1997;314:833.

9 Calverley PMA. Blood pressure, breathing, and the carotid body. Lancet 1999;354:969-70.

10 Ashwell M, Cole TJ, Dixon AK. Ratio of waist circumference to height is strong predictor of intra-abdominal fat BMF 1996;313:559-60.

11 Hoegholm A, Eidemak I, Kristensen KS, et al. Clinical evaluation of the Takeda Medical (A \& D) TM 2420 ambulatory blood pressure monitor. Practical experience and comparison with direct and indirect measurements. Scand F Clin Lab Invest 1992;52:261-8.

12 Collins R, Peto R, MacMahon S, et al. Blood pressure, stroke, and coronary heart disease. Part 2. Short-term reductions in blood pressure: overview of randomised drug trials in the epidemiological context. Lancet 1990;335:82738 .
13 Verdecchia P, Schillaci G, Guerrieri M, et al. Circadian blood pressure changes and left ventricular hypertrophy in essential hypertension. Circulation 1990;81:528-36.

14 Weinsier RL, Norris DJ, Birch R, et al. The relative contribution of body fat and fat pattern to blood pressure level. Hypertension 1984;7:578-85.

15 Norton PG, Dunn EV. Snoring as a risk factor for disease: an epidemiological survey. BMF 1985;291:630-2.

16 Koskenvuo M, Kaprio J, Partinen M, et al. Snoring as a risk factor for hypertension and angina pectoris. Lancet 1985;i: 893-6. 17 Lugaresi E, Cirignotta F, Coccagna G, et al. Some disturbances. Sleep 1980;3:221-4.

18 Carlson J, Davies R, et al and the Working Group on OSA and Hypertension. Obstructive sleep apnea and blood pressure elevation. What is the relationship?. Blood Pressure 1993;2:166-82.

19 Hoffstein V, Rubinstein I, Mateika S, et al. Determinants of blood pressure in snorers. Lancet 1988;ii:992-4.

20 Hoffstein V, Mateika J. Evening-to-morning blood pressure variations in snoring patients with and without obstructive sleep apnea. Chest 1992;101:379-84.

21 Lavie P, Herer P, Hoffstein V. Obstructive sleep apnoea syndrome as a risk factor for hypertension: population study. BMF 2000;320:479-82.

22 Grunstein R, Wilcox I, Yang TS, et al. Snoring and sleep apnoea in men: association with central obesity and hyper-
tension. Int $f$ Obesity Relat Metab Disorders 1993;17:53340.

23 Young T, Peppard P, Palta M, et al. Population-based study of sleep-disordered breathing as a risk factor for hypertension. Arch Intern Med 1997;157:1746-52.

24 Hla KM, Young TB, Bidwell T, et al. Sleep apnea and hypertension. Ann Intern Med 1994;120:382-8.

25 Young T, Finn L, Hla KM, et al. Snoring as part of a doseresponse relationship between sleep-disordered breathing response relationship between sleep-disor.
and blood pressure. Sleep 1996;19:S202-5.

26 Wilcox I, Grunstein RR, Hedner JA, et al. Effect of nasal continuous positive airway pressure during sleep on 24-hour blood pressure in obstructive sleep apnea. Sleep 1993;16:539-44.

27 Minemura H, Akashiba T, Yamamoto H, et al. Acute effects of nasal continuous positive airway pressure on 24-hour blood pressure and catecholamines in patients with obstructive sleep apnea. Intern Med 1998;37:1009-13.

28 Davies RJO, Crosby J, Prothero A, et al. Ambulatory blood pressure and left ventricular hypertrophy in untreated obstructive sleep apnoea and snoring, compared to matched controls, and their response to treatment. Clin Sci 1994;86:417-24. 